\title{
«O RETORNO É O MOVIMENTO DO TAO»: UMA ABORDAGEM DIALÉCTICA DA EFICÁCIA ORGANIZACIONAL
}

\author{
Miguel Pina e Cunha ${ }^{1}$ \\ Arménio Rego ${ }^{2}$
}

Resumo: Frequentemente, as discussões sobre a eficácia organizacional transmitem a ideia de que algumas organizações são mais eficazes do que outras. Neste trabalho, o ponto de partida é distinto: algumas organizações estão mais eficazes que outras. A eficácia é vista, por conseguinte, como um processo e não como um resultado estável. Para explorar esta perspectiva dinâmica, recorremos à filosofia chinesa do taoísmo. Algumas noções simples são usadas para discutir como eficácia e ineficácia, mais do que estados independentes, podem afinal ser as duas faces de um mesmo processo.

Palavras-chave: eficácia, ineficácia, taoísmo, processos organizacionais, paradoxos.

Inversion is the Movement of the Tao: A dialectical analysis of organizational effecttiveness (Abstract): Discussions on organizational effectiveness frequently transmit the idea that some organizations are more effective than others. In this work we challenge this idea and suggest that some organizations may be more effective than others but are becoming something else. Effectiveness is viewed, as such, as a process rather than as a stable state. To explore this perspective, we use the ancient Chinese philosophy of Taoism. Some simple notions are considered to discuss how effectiveness and efficiency, more than independent states, can instead be taken as two faces of the same process.

Key-words: effectiveness, in-effectiveness, taoism, paradoxes, organizational processes.

\footnotetext{
${ }^{1}$ Faculdade de Economia, Universidade Nova de Lisboa, Lisboa. A correspondência relativa a este artigo deverá ser endereçada a Miguel Pina e Cunha, Faculdade de Economia, Universidade Nova de Lisboa, Rua Marquês de Fronteira, 20, 1099-038 Lisboa - Portugal, E-mail: mpc@fe.unl.pt

Miguel Cunha agradece o apoio da Fundação para a Ciência e a Tecnologia (Bolsa FCT POCTI/GES/48967/2002).

2 Departamento de Economia, Gestão e Engenharia Industrial, Universidade de Aveiro, Aveiro.
}

PSICOLOGIA, Vol. XXI (1), 2007, Edições Colibri, Lisboa, pp. 107-131. 
"O retorno é o movimento do tao."

Lao-Tse (2000, p. 53)

\section{A Centralidade do Tema e a Controvérsia}

A eficácia é um tema central na gestão de empresas e, por conseguinte, nas teorias da organização e da gestão. Walton e Dawson (2001) sublinharam esta centralidade, aduzindo que "[o] constructo da eficácia organizacional continua a ser um tema recorrente tanto para os académicos como para os gestores. Situa-se no cerne de todas as teorias organizacionais, proporciona a última variável dependente na pesquisa empírica, e facilita as acções dos gestores e as respectivas justificações" (p. 177).

Esta perspectiva algo "romântica" não reflecte, todavia, uma "história longa e tortuosa" (Herman \& Renz, 1999, p. 108) e repleta de controvérsia. Também não se compagina com o estado actual do campo, que se caracteriza pela diversidade de modelos e pela profusão de critérios (Henri, 2004; Walton \& Dawson, 2001). O conceito é complexo e pode ter significados diferentes para diferentes organizações, para a mesma organização em momentos diferentes ou para diferentes partes interessadas (e.g., Kirby, 2005). Acresce que, mesmo quando convergem a propósito do significado do conceito, os investigadores e os gestores não perfilham idênticas concepções acerca dos melhores critérios para medi-la (Henri, 2004; Walton \& Dawson, 2001).

Neste trabalho, redigimos uma alternativa ou complemento explicativo que permita compreender e melhor lidar com esta controvérsia. Mais especificamente, analisamos o conceito de eficácia organizacional numa perspectiva dialéctica. O objectivo do texto é o de apresentar os paradoxos e as contradições inerentes à eficácia enquanto ideia e prática. Para reflectir criticamente sobre o tema, analisamo-lo de acordo com as lentes teóricas proporcionadas pelo taoísmo, um sistema de pensamento e uma das quatro maiores religiões da China. A ideia para a explicação dialéctica da eficácia decorre da afirmação atribuída a Lao-Tse (2000, p. 53) e citada na abertura: "O retorno é o movimento do tao". A afirmação expõe com clareza duas ideias cruciais para o entendimento da eficácia: movimento (processo, dinamismo) e retorno/inversão. Este último termo pareceu-nos particularmente interessante por ecoar um ponto porventura merecedor de maior atenção na literatura do comportamento organizacional: os processos ou resultados organizacionais podem inverter-se e dar lugar ao seu oposto. Esta ideia pa- 
receu-nos apropriada para o estudo do tema, dada a frequência com que organizações modelares se transformam em exemplos a evitar.

Sendo estes os objectivos traçados, começamos por apresentar algumas das principais conclusões obtidas no âmbito da literatura. Procedemos, também, à apresentação de algumas conclusões consensuais sobre a eficácia organizacional. Seguidamente, discutimos o problema da eficácia de acordo com a perspectiva dialéctica proporcionada pela filosofia taoísta. Esta é apenas uma dentre as múltiplas maneiras de analisar a eficácia. Não se pretende apresentá-la como a melhor abordagem, mas apenas como uma das formas de representar o fenómeno, entre outras possíveis (Van de Ven \& Poole, 1995). Com o texto, contribuímos para enriquecer a literatura com a explicitação de uma das cambiantes possíveis da abordagem dialéctica das organizações, procurando imprimir ao texto um cariz capaz de articular teoria e prática.

\section{Uma Breve História}

Durante os anos 1950 e os primórdios dos anos 1960, o tópico da eficácia foi, geralmente, negligenciado pelos investigadores. Entre os argumentos justificativos desta posição, surgia o que advogava que as considerações de eficácia representavam, apenas, interesses de natureza aplicada e prática, mais do que teórica (Scott, 1992). Todavia, gradualmente, os investigadores começaram a aceitar a existência de fundamentos teóricos para um tal campo de análise. Por exemplo, ao admitir-se que certas estruturas organizacionais são mais adequadas do que outras para determinadas tarefas ou ambientes (Lawrence \& Lorsch, 1967; Thompson, 1967), a pergunta incontornável não podia deixar de ser: adequadas em que sentido? Acresce que, para além da pertinência teórica, a eficácia foi adquirindo elevado interesse prático: a competição à escala global, com as consequentes exigências de produtividade e competitividade, transformou-a num critério de sobrevivência organizacional (Scott, 1992).

Daqui resultou um especial florescimento de estudos, durante a segunda parte da década de 1960 e a primeira metade de 1970. Admitia-se, então, a possibilidade de construir medidas gerais de desempenho, e de distinguir facilmente as empresas de baixa e de elevada eficácia (Meyer \& Gupta, 1994). Todavia, a partir de meados da década de 1970, os estudos quase eclipsaram (Meyer \& Gupta, 1994). Talvez a causa principal tenha provindo dos resultados persistentemente demonstrativos de que: (a) a eficácia é multidimensional; (b) não é possível obter uma medida inequivocamente adequada; (c) as medidas existentes não se correlacionam entre si, podendo mesmo revelar relações contraditórias. 
O conceito de eficácia organizacional tornou-se, então, suspeito (Meyer \& Gupta, 1994), situação que conduziu Hannan e Freeman (1977) a afirmarem que o tópico se localizava fora das fronteiras da pesquisa científica. Pouco tempo depois, Miles (1980, pp. 355-356) não podia ser mais claro: "Um breve olhar pela literatura organizacional revela a existência de escasso acordo acerca do que realmente significa a eficácia organizacional (...). Esta confusão é mais do que semântica. Com efeito, as divergências acerca das definições constituem um impedimento para o desenvolvimento do conhecimento das organizações complexas. As diferenças entre os critérios usados para medir a eficácia tornam impossível comparar os resultados dos vários estudos".

Na mesma altura, Connolly, Conlon e Deutsch (1980, p. 211) afirmavam: "A investigação em eficácia organizacional parece sofrer de desordem conceptual. Recentes revisões de literatura chegam, invariavelmente, a conclusões negativas (...). Alguns chegam a argumentar que o conceito não é pesquisável, devendo permanecer mais no domínio conceptual do que como constructo empiricamente relevante (...). Nós não temos nenhum argumento contra tal pessimismo, embora julguemos que a esperança não está completamente perdida".

Decorridos seis anos, Cameron (1986, p. 539) mantinha um tom idêntico: "Apesar da popularidade da eficácia organizacional, a literatura continua a revelar grande confusão a propósito da sua definição, âmbito e critérios apropriados de avaliação". Algum tempo depois, Meyer e Gupta (1994) afinavam pelo mesmo diapasão. Os autores enfatizavam, designadamente, três pontos essenciais. Primeiro: existem inúmeras medidas de desempenho (e.g., financeiras, de qualidade). Segundo: as medidas mais comuns tendem a não se correlacionar entre si. Terceiro: nenhuma medida de desempenho permanece por longo tempo, sendo que aquelas que recebem maior atenção dos gestores mudam radicalmente ao longo do tempo. A ilação retirada pelos autores foi clara: "O puzzle do desempenho organizacional permanece sem resolução. Sabemos acerca dele pouco mais do que sabíamos há 20 anos atrás" (p. 311).

Algum tempo depois, Banner e Gagné (1995, p. 102) revelavam que o tema permanecia no mesmo campo de ambiguidade e confusão: "Não há nenhum tópico nas ciências sociais aplicadas acerca do qual haja tão reduzido acordo como o verificado a propósito da eficácia organizacional. Todos concordamos em que devemos erigir organizações 'eficazes', mas ninguém concorda acerca do que é a eficácia". E acrescentavam: "Este baixo nível de acordo não existe, apenas, no que concerne à definição também ocorre a respeito dos modos de medida".

Os problemas e as dificuldades que daqui advêm e assomam perante os trabalhos dos investigadores são claros: "Dado que muitas das medidas de eficácia propostas não se correlacionam entre si, ou se relacionam mes- 
mo negativamente, não podemos esperar encontrar explicações gerais que nos permitam distinguir as organizações eficazes das ineficazes" (Scott, 1992, p. 360). Uma das evidências mais paradigmáticas das dificuldades de clarificação que temos vindo a expor pode ser encontrada na famigerada obra de Peters e Waterman (In Search of Excellence, 1982) e nos acontecimentos que se lhe seguiram: algumas das empresas consideradas excelentes revelaram, pouco tempo depois, que tinham "perdido o brilho".

Este breve relato "histórico" não perdeu validade nos anos mais recentes. Diversos autores argumentam, por exemplo, que: (a) estamos em présença de uma abstracção hipotética e uma construção social, mas não de uma realidade objectiva (Herman \& Renz, 1998, 1999; Walton \& Dawson, 2004); (b) os académicos e os práticos divergem sobre o conceito de eficácia e sobre os critérios para a sua medição (Henri, 2004; Walton e Dawson, 2004); (c) diferentes tipos de organizações (e.g., públicas $v s$. privadas) requerem diferentes critérios de medida de eficácia (Parhizgari \& Gilbert, 2004); (d) diferentes tipos de stakeholders invocam diferentes perspectivas quando avaliam a eficácia (Herman \& Renz, 1998; Walton \& Dawson, 2001).

\section{Cinco Modelos de Eficácia Organizacional}

Uma forma simples de definir eficácia é considerá-la como o grau em que uma organização realiza os seus objectivos (Etzioni, 1964). Uma organização eficaz é aquela que faz as coisas certas (doing the right thing). Este conceito é normalmente distinguido do de eficiência, o rácio entre inputs e outputs (veja algumas definições relevantes no Quadro 1). Uma organização eficiente é aquela que faz as coisas bem feitas, ou seja, que realiza os seus objectivos com a menor quantidade de recursos (doing things right).

Esta definição de eficácia comporta, no entanto, diversas dificuldades, tendo vindo a ser complementada por outros modelos, mais refinados. Deles se ocupa a presente secção. Embora diversas tipologias existam para a classificação desses modelos, uma das mais apelativas considera cinco grandes tipos (Henri, 2004). O modelo tradicional é o dos objectivos (Etzioni, 1964; Goodman et al., 1977). Assenta numa visão que concebe a organização como um conjunto racional de arranjos orientados para o alcance de objectivos. Deste ponto de vista, a organização eficaz é aquela cujos resultados coincidem com os objectivos. Este modelo assenta em várias premissas que, na teoria organizacional, têm sido consideradas problemáticas (Herman \& Renz, 1999): (a) as organizações têm objectivos; (b) estes objectivos podem ser identificados/descobertos; (c) os objectivos abstractos podem ser convertidos em medidas específicas e objectivas; (d) os dados relevantes para estas medidas podem ser coligidos, processados e aplicados de modo apropriado e atempado. 
Quadro 1. Alguns conceitos importantes

ganização alcança os seus objectivos. Todavia, não há consenso sobre a matéria. Por exemplo, outras definições focalizam-se também nos meios que permitem alcançar tais fins.

Alguns autores equivalem desempenho e eficácia (Henri, 2004), mas outros apontam em sentido distinto. Por exemplo, Venkatraman e Ramanujam (1986) consideram o desempenho como um subconjunto do conceito

Desempenho mais geral de eficácia. Por seu turno, Hannan e Freeman (1977) aduzem que o desempenho representa a quantidade e a qualidade do output, ao passo que a eficácia é o grau em que os resultados coincidem com os objectivos.

Corresponde ao ratio entre inputs e outputs. Uma organização é tanto Eficiência mais eficiente quanto mais outputs consegue alcançar com poucos inputs. De modo mais específico, a eficiência reflecte a comparação entre algum aspecto do desempenho e os custos incorridos para alcançá-lo.

É a quantidade ou volume do produto ou serviço proporcionados pela

Produtividade empresa. Pode ser medida aos níveis individual, grupal e/ou organizacional.

\begin{tabular}{ll}
$\begin{array}{l}\text { Vantagem } \\
\text { competitiva }\end{array}$ & $\begin{array}{l}\text { Este conceito está fortemente associado ao de competências distintivas. } \\
\text { Procura explicar por que determinadas organizações são mais competiti- } \\
\text { vas do que outras, pelo facto de possuírem e usarem activos/recursos sin- } \\
\text { gulares e/ou denotarem forte alinhamento com o mercado. }\end{array}$ \\
$\begin{array}{l}\text { Agilidade } \\
\text { organizacional a capacidade da organização de responder rápida e apropriadamente às } \\
\text { mudanças rápidas que se lhe deparam. A organização ágil é a que avalia } \\
\text { a envolvente, constrói sentido sobre o que está a ocorrer, e rapidamente } \\
\text { mobiliza e afecta recursos e pessoas para gerir essas ocorrências. }\end{array}$ \\
$\begin{array}{l}\text { É a capacidade para responder apropriadamente a mudanças disruptivas. } \\
\text { A organização resiliente é capaz de absorver os choques e as surpresas, }\end{array}$ \\
$\begin{array}{l}\text { Resiliência } \\
\text { erganizacional } \\
\text { dentro e forativamente da organização, e executa a mudança transformacional } \\
\text { (e.g., repensando a sua identidade e o seu propósito e redesenhando-se } \\
\text { em conformidade). }\end{array}$ \\
\hline
\end{tabular}

O modelo sistémico, ainda que reconheça a importância dos objectivos, enfatiza a necessidade de atender aos meios que são requeridos para alcançá-los (Miles, 1980; Yuchtman \& Seashore, 1967). Esta concepção assenta na abordagem dos sistemas abertos, nos termos da qual os inputs, o processo de transformação e os outputs são parte de um todo e não elementos independentes.

$O$ modelo dos constituintes expande o âmbito dos dois modelos anteriores, acrescentando as expectativas dos grupos de interesses (stakeholders) 
que gravitam em torno da organização (Connolly, Colon \& Deutsch, 1980). Deste ponto de vista, os proprietários, os empregados, os clientes, os fornecedores, os credores, as entidades públicas e a comunidade são entidades cujos interesses devem ser satisfeitos para que a organização seja eficaz e sobreviva. Todavia, daqui decorrem diversas dificuldades e, porventura, impossibilidades, quando a satisfação dos interesses de alguns stakeholders impede o alcance dos interesses de outros.

$O$ modelo dos valores contrastantes é, porventura, um dos mais amplamente reconhecidos na literatura actual. Constitui uma síntese e uma extensão dos modelos anteriores (Quinn \& Rohrbaugh, 1983). Encara a avaliação da eficácia como um exercício assente em três tipos de valores, cada um correspondente a uma dimensão. A primeira dimensão reflecte o focus, que pode ser interno (e.g., moral da equipa) ou externo (e.g., crescimento da empresa). A segunda dimensão contrasta controlo e flexibilidade. A terceira dimensão refere-se ao binómio meios-fins. Por exemplo, a coesão é uma medida relacionada com os meios, enquanto o lucro se relaciona com fins. Quando se cruzam as dimensões interna-externa e controlo-flexibilidade, emergem quatro modelos ou clusters (racional, relações humanas, prócessos internos, sistema aberto), no seio dos quais surgem medidas/critérios que podem reportar-se a meios ou a fins.

$O$ modelo de ineficácia focaliza-se nos factores que inibem o desempenho (Cameron, 1984). Concebe a organização como um conjunto de problemas e falhas. Considera que é mais fácil, rigoroso, consensual e benéfico identificar problemas e falhas do que critérios de eficácia. Por conseguinte, a eficácia é interpretada como a ausência de factores de ineficácia.

Cada um destes cinco modelos denota vantagens e desvantagens. Pode mesmo ser útil para diferentes fases do ciclo de vida de uma organização. Pode ser mais pertinente em determinadas culturas nacionais do que noutras. E inclui alguns elementos que não estão presentes nos outros. Todavia, nenhum contempla o significado total da eficácia (Cameron, 1984; Walton \& Dawson, 2001).

\section{Gestão da Eficácia: Algumas Zonas de Consenso}

A medição e a gestão da eficácia e da eficiência não são, pois, tarefas fáceis. Desde logo, porque pode ser difícil definir objectivos ou medidas de eficiência. Por exemplo, medidas relevantes do ponto de vista operacional podem revelar-se contraproducentes do ponto de vista dos clientes. Deverá um restaurante medir o seu resultado pelo número de refeições servidas? Se for este o critério, como se sentirá o cliente que gosta de jantar tranquilamente e sem se sentir pressionado ao ser "convidado" para abandonar rapi- 
damente a sala, em nome da eficiência? Será o critério tão bom para o cliente como para o restaurante?

Dificuldade idêntica pode ser encontrada a propósito dos critérios da rentabilidade e da quota de mercado. Com frequência, o alcance de uma maior quota de mercado (e.g., pela via da diminuição dos preços e/ou de mais custos com publicidade) resulta na quebra na rentabilidade nas vendas. Quando se tomam em atenção os critérios de vários stakeholders, a dificuldade reitera-se. Por exemplo, não é certo que a empresa possa enfrentar dificuldades em conciliar os objectivos/interesses dos accionistas, dos empregados, dos gestores e da comunidade? E que critérios são finalmente escolhidos e seguidos pela empresa quando alguns gestores preferem a sobrevivência da empresa, ao passo que outros se focalizam mais no curto prazo?

Apesar de toda esta complexidade do tópico, alguns aspectos podem ser considerados consensuais (Cameron, 1986; Henri, 2004; Scott, 1992):

1. A eficácia é um objectivo final de todas as teorias da organização. Apesar das críticas que referem a dificuldade de entender o que significa exactamente "eficácia", tanto os gestores como os investigadores consideram importante distinguir organizações e gestão de alta qualidade (eficazes) e de baixa qualidade (ineficazes).

2. Não há apenas uma representação da eficácia. As organizações podem ser vistas de formas muito distintas. Quando muda a forma como as olhamos, mudam os critérios de eficácia. Se a organização for entendida como um mercado transaccional, os critérios de eficácia serão uns (e.g., quantidade de transacções, custos de transacção, ganhos por transacção); se for entendida como uma comunidade humana, serão outros (e.g., medidas sociais, duração da relação de emprego). A lógica dos accionistas (a organização serve para criar o maior valor para os accionistas) produz critérios muito diversos dos da lógica das partes interessadas (a organização deve corresponder de forma tão satisfatória quanto possível aos interesses de um conjunto alargado de partes interessadas, como os clientes, o Estado, a comunidade envolvente ou o ambiente natural).

3. O consenso sobre os melhores critérios (ou os critérios suficientes) de eficácia é impossível de obter. Os "melhores" critérios não existem de forma objectiva, podendo mesmo provir dos (des)equilíbrios de poder e da negociação política que se desenrola entre os actores organizacionais (Scott, 1992). Eles dependem das preferências e dos valores dos actores, que podem, aliás, ser contraditórios com as preferências de outros actores. O accionista de uma empresa valoriza critérios que não são necessariamente da preferência do operariado da mesma. 
Além disso, os critérios variam ao longo do tempo. O mesmo director geral pode valorizar especialmente o crescimento da quota de mercado num determinado momento, para num período subsequente preferir manter apenas os clientes mais rentáveis. Por outro lado, os indivíduos podem ter preferências eventualmente contraditórias, como um aumento da qualidade do serviço e uma redução de custos. Por todas estas razões, a identificação dos "melhores" critérios constitui uma impossibilidade.

4. A validade de um modelo depende das circunstâncias. Considerando os aspectos já mencionados, não é possível descortinar um modelo de eficácia que seja o melhor em todas as circunstâncias. Diferentes modelos serão adequados em diferentes circunstâncias, em diferentes contextos, em diferentes sectores, em diferentes momentos, em diferentes fases do ciclo de vida das organizações.

5. Uma das vias mais adequadas para lidar com a medição da eficácia consiste em recorrer a vários critérios e indicadores. Estes devem ser escolhidos de acordo com as circunstâncias e devem ser mudados à medida que estas se alteram. Por exemplo, para obter legitimidade institucional (Meyer \& Rowan, 1977), a organização pode ver-se compelida a recorrer a critérios usados pelos concorrentes ou requeridos por instituições reguladoras. Embora possa ser eficaz à luz de um dado critério (e.g., lucros), a organização incorre no risco de afectar a sua prossecução se, entretanto, não aderir a esse outro critério institucionalmente estimulado.

6. Para se avaliarem os modelos de eficácia e se compreenderem as especificidades dos critérios usados pelas organizações, importa atender a sete questões críticas: (a) a eficácia está a ser medida na perspectiva de quem? (b) em que domínio de actividade está centrada a avaliação? (c) qual o nível de análise (e.g., individual, grupal, orgaNizacional) que está a ser considerado?; (d) qual o propósito da avaliação da eficácia? (e) qual o horizonte temporal considerado? (f) que tipo de dados estão a ser utilizados? (g) qual o referente perante o qual é avaliada a eficácia? A resposta a estas questões revela-se crucial. Por exemplo, intervenções apenas produzidas ao nível micro poderão não ter impactos macro-organizacionais. Ilustrativamente, é o que pode suceder quando a formação em liderança esbarra na persistência dos sistemas de recompensa. Da mesma forma, se a avaliação está centrada nos custos com o pessoal, o resultado previsível será um processo de downsizing para reduzir os custos. 
Em suma, a tentativa de gerir (e medir) a eficácia de uma forma objectiva e rigorosa tem esbarrado num conjunto de dificuldades, ambiguidades e contradições. Toda a simplificação e linearização do processo é realizada à custa da perda de parte da complexidade inerente ao conceito e ao processo que o concretiza. Na secção seguinte, entramos no âmago do trabalho, apresentando uma abordagem dialéctica da eficácia, a qual ajuda a compreender o carácter contraditório e paradoxal da eficácia. Para o efeito, procedemos a uma análise do tema baseada em alguns elementos do sistema de pensamento taoísta.

\title{
Uma Perspectiva Dialéctica: O Tao da Eficácia
}

\author{
"No meu princípio está o meu fim. Sucessivamente \\ Casas elevam-se e caem, desmoronam-se, são alargadas, \\ São removidas, destruídas, restauradas, ou em seu lugar \\ Está um campo aberto, ou uma fábrica, ou um desvio \\ Velha pedra para novo edifício, velha madeira para novos fogos" \\ East Coker, \\ T. S. Eliot
}

\section{O taoísmo}

Embora a noção de eficácia evoque habitualmente um conjunto de associações positivas, ela pode ser fonte de... ineficácia. E, simetricamente, a ineficácia pode ser a "mãe" da eficácia. Nesta relação tensa, paradoxal e dialéctica entre eficácia e ineficácia, ecoam ressonâncias taoístas. Se, como afirmava Lao-Tse, o suposto fundador do taoísmo, o retorno é o caminho do Tao, a eficácia é a fonte da ineficácia e vice-versa (uma introdução ao taoísmo pode ser encontrada, por exemplo, em Oldstone-Moore, 2005).

O taoísmo, com origem na China antiga, é um sistema de pensamento que, entre outros aspectos, se baseia na ideia de que cada fenómeno gera o seu oposto. A obra Tao Te King é, logo a seguir à Bíblia, o clássico mais traduzido do mundo (Wing, 1986). Em Portugal, existe uma tradução da editorial Estampa e outra da Lyon Edições. De uma forma simples, o livro explica uma força de desenvolvimento denominada Tao, que opera através do universo. Descreve, também, o poder pessoal que resulta de se estar em sintonia com o Tao, que é conhecido por Te. A palavra Ching ou King significa "clássico" (Wing, 1986, p. XII). 
Lao-Tse acreditava que o conhecimento dos modelos da natureza traria discernimento para os modelos paralelos no comportamento humano: "tal como a Primavera se segue ao Inverno, na natureza, o crescimento segue-se à repressão, na sociedade; tal como demasiada gravidade fará desmoronar uma estrela, demasiada possessividade desmoronará uma ideia" (Wing, 1986, p. XV). Observando as leis da natureza, Lao-Tse compreendeu que uma força excessiva numa determinada direcção tende a despoletar o crescimento da força oposta, pelo que o uso da força não pode ser a base para estabelecer uma forte e duradoura fundação social.

Lao-Tse viu que o campo unificado de forças que denominou Tao não podia ser expresso de forma lógica e analítica. Por conseguinte, transmitiu o seu pensamento através do paradoxo. As oitenta e uma passagens do seu pequeno livro estão repletas de frases contraditórias (e.g., "Tira vantagem do que lá está, fazendo uso do que não está"). Lao-Tse usou o paradoxo para explicar os modelos e os ciclos da vida, a paridade e a complementaridade - que, do seu ponto de vista, se superimpunham na realidade pelas forças físicas do universo. O mais notável destes modelos é o da polaridade (Wing, 1986).

\section{A polaridade do Yin e do Yang}

O sistema de pensamento taoísta ajuda a compreender que aqueles que por vezes são tomados como fenómenos contrários são, de facto, parte de uma unicidade: vida e morte, frio e calor, figura e fundo, positivo e negativo. Não é possível conceber o Bem na ausência do Mal. O frio revela-se pela existência do calor. A noite é o culminar do dia. É desta tensão entre opostos que decorre o curso da natureza, o Tao. O termo Tao sugere que o fluxo da natureza é um processo contínuo, moldado pela interacção contínua entre Yin e Yang. Yin e Yang representam, respectivamente, os lados sombrio e iluminado de uma colina e simbolizam o modo como as energias opostas, mas complementares, interagem. A interacção entre Yin e Yang revela também como a acumulação de uma das energias reverte um dia o movimento do Tao: o retorno é o movimento do Tao. Neste sentido, tudo o que vive está num processo de se tornar algo diferente.

Yin e Yang, os opostos primordiais, estão na base de toda a mudança. O seu carácter dinâmico é ilustrado no antigo símbolo chinês T'ai-chi T'u ou Diagrama do Fundamento Supremo (ver Figura 1; ver também Capra, 1975, pp. 113-114; Morgan, 1986, pp. 255-257). 


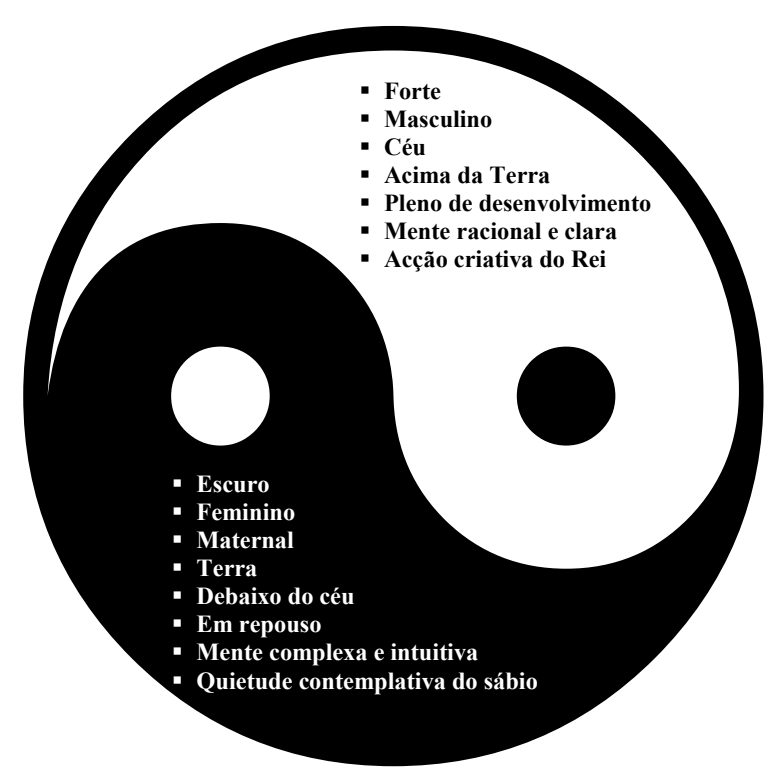

Figura 1: T'ai-chi T'u ou Diagrama do Fundamento Supremo

O diagrama proporciona uma representação da forma como o lado escuro, o Yin, se relaciona com o lado claro, o Yang. Entre Yin e Yang estamos em presença de uma simetria, mas dois elementos devem ser considerados: em primeiro lugar, trata-se de uma simetria dinâmica, rotacional. $\mathrm{O}$ movimento de rotação sugere a existência de um movimento cíclico contínuo: o Yin e o Yang sucedem-se. Em segundo lugar, os pontos de sinal contrário presentes em cada uma das forças simbolizam o facto de cada uma delas conter o seu oposto. Ou seja, em cada uma está a semente do seu contrário. Quando uma força atinge o seu extremo, dá lugar à outra. Depois de atingir o meio-dia, a luz começa a dar origem à escuridão. 


\section{Implicações para as organizações}

As implicações de uma lógica taoísta para a compreensão das organizações são claras e profundas. Na sua complexidade paradoxal, o sistema taoísta desafia algumas das ideias estabelecidas e projecta nova luz sobre o funcionamento das organizações. Eis algumas das possibilidades de uma leitura taoísta da organização:

- Os opostos não são estados irreconciliáveis, mas partes complementares de uma mesma unidade. Por exemplo, de acordo com o stakeholder $\mathrm{A}$, uma organização pode ser eficaz à luz de um dado critério, e ineficaz à luz de outro. Todavia, na perspectiva do stakeholder $\mathrm{B}$, a interpretação pode ser a oposta. Sucede que esta paradoxalidade não é necessariamente perversa. Aliás, tal como Meyer e Gupta (1994, p. 550) aduziram, a eficácia organizacional "é inerentemente paradoxal. Para ser eficaz, uma organização deve possuir atributos que sejam simultaneamente contraditórios, mesmo mutuamente exclusivos (...). As organizações altamente eficazes são as que satisfazem as expectativas dos seus diversos constituintes, mesmo que essas expectativas sejam contraditórias".

- As organizações são estados instáveis, mais do que realidades estáveis. Por outras palavras, as organizações são processos cujos contornos, conteúdos e resultados se alteram com o decurso do tempo e as circunstâncias.

- A mudança - e não a resistência à mudança - é a norma da vida organizacional. Mas ambas coexistem - e cada uma necessita da outra. E mesmo as resistências não bloqueiam as mudanças - antes originam outras mudanças, por exemplo, uma progressiva ossificação do sistema organizacional.

- As estruturas são representações menos adequadas da existência organizacional do que os processos.

- Não é possível conhecer um processo sem conhecer o outro processo que se lhe opõe.

- Cada processo contém as sementes da sua própria destruição.

- A glória é o prenúncio da decadência. $\mathrm{E}$ a crise pode ser o gérmen da futura glória.

- Uma organização "obcecada" com (determinados critérios de) eficácia pode permitir o desenvolvimento das forças que fazem gerar a ineficácia. E a organização que encontra oportunidades na ineficácia pode descobrir caminhos para a eficácia. 
A este propósito, cabe sublinhar os comentários redigidos por Wing (1986) à passagem n. ${ }^{\circ} 9$ do livro de Lao-Tse. Numa alusão a matérias bastante próximas das que emergem na liderança e nas organizações, o autor/tradutor afirmou que, depois de desenvolver situações e alcançar sucesso, os sábios ${ }^{3}$ não tardam em experimentar "o inevitável ciclo do declínio. Sabem que, se pararem para se identificarem com as suas concretizações, o seu crescimento interior terminará e a sua queda começará. Nada é estático na natureza. Tudo o que atinge a sua plena maturidade - sejam plantas e animais ou planetas e estrelas - tem necessariamente de entrar em declínio. Por isso, os sábios nunca param de crescer e nunca acumulam fardos sociais ou materiais que abrandem o seu progresso. Quando o seu trabalho está feito, passam para a tarefa seguinte. Deste modo, desenvolvem grandeza e poder". O texto de Lao-Tse a que Wing se refere (e que intitulou "Transcender o declínio") é paradigmático para os propósitos do presente artigo, parecendo apelar aos gestores e às organizações para que se mantenham atentos e cientes de que a abundância e o sucesso podem ser inimigos do sucesso de amanhã. Eis o texto:

"Manter a abundância

Não é tão bom como parar a tempo.

A astúcia que penetra

Não pode proteger por muito tempo.

Uma casa cheia de ricos

Não pode ser defendida.

Orgulho no luxo e posição

É não notar o colapso.

Retirar-se quando o sucesso é alcançado

É o Tao da Natureza".

Acrescente-se aqui um extracto da passagem 42, que Wing intitulou "Conhecer a polaridade", e no qual Lao-Tse escreveu:

"Assim, na Lei Natural,

Alguns perdem e deste modo lucram

Alguns ganham e desse modo perdem".

As potencialidades de uma abordagem taoista têm sido exploradas por diversos autores, mesmo que a designação não seja usada. Por exemplo,

\footnotetext{
${ }^{3} \mathrm{O}$ autor/tradutor usa a expressão "indivíduos desenvolvidos", e não sábios - embora tenha reconhecido esta tradução como uma possibilidade aceitável. Pareceu-nos que, para os leitores deste artigo, o termo "sábio" seria mais ajustado.
} 
a análise organizacional levada a cabo por Karl Weick (e.g., Weick, 1979) aborda muitos dos temas enunciados na lista anterior. Greiner (1972) ilustrou o modo como a solução de hoje pode ser o problema de amanhã. Morgan (1986) referiu explicitamente as possibilidades de uma leitura taoista das organizações. Tsoukas e Chia (2002) exploraram a natureza processual das organizações e o processo que as leva a tornarem-se algo diferente daquilo que são. Kets de Vries (2005) contrastou o lado claro com o lado escuro da liderança. E Kaplan e Kaiser (2003) escreveram sobre os perigos de uma visão dualista da organização.

A forma como cada autor aborda os paradoxos organizacionais revela a sua perspectiva perante a existência organizacional: (a) alguns autores argumentam a necessidade de contrariar paradoxos; (b) outros revelam a sua inevitabilidade; (c) e um terceiro grupo argumenta que a aceitação dos paradoxos pode ser uma fonte de possibilidades/oportunidades para a gestão de empresas (Cunha, 2006). A ideia de que os paradoxos podem ser uma fonte de compreensão da organização e de melhoria da gestão revela-se, neste sentido, próxima da filosofia taoísta. A aceitação do paradoxo como força criativa ajuda, por sua vez, a reenquadrar e a melhor compreender fenómenos que, numa visão teleológica, não passam de anomalias. Por exemplo, a improvisação é um complemento do planeamento (Cunha, Cunha \& Kamoche, 1999); o inesperado é o reverso expectável do esperado (Cunha, Clegg \& Kamoche, 2005); a descoberta acidental representa o outro lado da procura deliberada (Cunha, 2005a); a utilização criativa de recursos equilibra o desenvolvimento de uma lógica de recursos únicos (Cunha, 2005b).

Neste trabalho, interessa-nos explorar o caso particular da relação contraditória e paradoxal entre eficácia e ineficácia. Apesar da dominância da visão teleológica que apresenta as organizações como evoluindo desejavelmente para estados de eficácia progressivamente mais elevados, existe um interessante potencial na análise taoísta da relação entre eficácia e ineficácia. Nesta perspectiva, a eficácia e a ineficácia são processos gémeos, mais do que contrários inconciliáveis. Nas secções seguintes exploramos duas possibilidades: a eficácia como fonte da ineficácia e a ineficácia como fonte da eficácia.

\section{Polaridade: Eficácia $\rightarrow$ ineficácia}

A eficácia tende a revelar-se um estado delicado. Entre os méritos da teoria ecológica das organizações conta-se o de revelar que a mudança organizacional é mais um processo supra-organizacional (ocorrendo ao nível de populações) do que um processo organizacional. Ou seja, as 
mudanças das organizações ocorrem através de substituição e não de adaptação (Hannan \& Freeman, 1977). Ou seja, estar adaptado é diferente de ser ou permanecer adaptado. Como tal, a eficácia, tradutora de um estado de alinhamento entre a oferta de uma organização e a procura do mercado, tende a revelar-se um estado transitório. A efemeridade da eficácia das organizações radica num conjunto de fontes. Ou, por outras palavras, a eficácia contém em si mesma as sementes da ineficácia. Nesta secção discutimos algumas das explicações para o processo.

Descontando o caso da maioria das organizações, que não conseguem alcançar os níveis de eficácia requeridos para sobreviver aos primeiros anos de existência (veja, para os exemplos opostos de organizações longevas, os trabalhos de Collins \& Porras, 1994; e de De Geus, 1997), concentrar-nos-emos, aqui, no caso das organizações que conseguem obter níveis elevados de eficácia. Essas organizações obtêm, pelo menos nos sectores mais tradicionais, níveis elevados de reprodutibilidade de processos. Por outras palavras, desenvolvem rotinas altamente aperfeiçoadas, as quais apresentam múltiplas vantagens: (a) níveis elevados de eficiência; (b) maior probabilidade de corresponder às expectativas dos clientes de forma adequada; (c) mestria dos processos e sentimentos de competência associados; (d) aperfeiçoamento de processos já executados de forma competente. As organizações eficazes tendem, por outras palavras, a melhorar aquilo que já fazem bem. Preferem a exploração das aprendizagens anteriores (exploitation) à aprendizagem por exploração de novos domínios (exploration). Esta distinção, proposta por James March (1991), é crucial para o entendimento da eficácia, sendo que, a longo prazo, a capacidade de adaptação organizacional requer tanto uma como a outra.

Todavia, a tentação da exploração das aprendizagens anteriores pode revelar-se um "doce veneno": a organização mantém-se na zona de conforto, explora as zonas de competência avançada e melhora o que já executa de forma competente. Se as vantagens desta abordagem são sedutoras, os riscos por ela comportados são portentosos. Vários autores procederam anteriormente ao seu estudo. Por exemplo, Danny Miller (1990) expôs o modo como as organizações eficazes podem tornar-se vítimas do seu próprio sucesso. A competência impele-as a estreitar as suas zonas de actuação, induzindo o ingresso num processo de simplicidade. De tal modo se deixam seduzir pelas suas próprias conquistas que, por vezes, tombam, vítimas delas. Ao processo, o autor atribuiu a designação de "paradoxo de Ícaro", por analogia à figura mitológica. O paradoxo sugere que o sucesso pode levar ao fracasso.

Várias explicações foram avançadas por Miller para interpretar este paradoxo. Entre elas, está a ideia de "memórias estruturais". De acordo com esta noção, as organizações criam memórias daquilo que funcionou bem no passado, e têm dificuldade em aceitar que essas "receitas" não são necessariamente adequadas para os desafios do presente e do futuro. A contiguidade entre memórias estruturais e comportamentos automáticos deve também 
ser considerada: se as memórias estruturais forem suficientemente fortes, as pessoas actuarão de forma automática e mentalmente "desligada" (Langer, 1989). Estruturas complexas tendem a estimular pensamentos simples, isto é, pouco sofisticados (Cunha \& Rego, 2004). Se Peters e Waterman (1982) ilustraram a via para a excelência, Miller (1990) revelou os perigos da excelência, que, aliás, vitimou algumas das empresas entronizadas na obra $\mathrm{Na}$ Senda da Excelência.

As conclusões de Miller são congruentes com outros trabalhos realizados no âmbito da gestão. Prahalad (2004) apresentou o conceito de lógica dominante, um paradigma organizacional que impede os gestores de interpretarem a realidade fora do âmbito desse paradigma. Mesmo que outros actores na organização tenham interpretações distintas (e porventura mais eficazes), o facto de a equipa de gestão de topo desenvolver uma cognição partilhada pode fechar a possibilidade de emergência de soluções heterodoxas e externas ao paradigma. Dito de outra forma: o foco e a aceitação de uma lógica paradigmática desviam a atenção das zonas da periferia onde incubam os movimentos ameaçadores do statu quo. A atenção ao centro desvia o olhar da periferia (Chia, 2005). E os actores organizacionais que alertam para os riscos acabam por ser negligenciados, tomados como "fracos jogadores de equipa" e postergados - porque, ao colidirem com o paradigma dominante, criam instabilidade e desconforto. O conceito de "mente organizacional", que impede a organização de prestar atenção a sinais e a fenómenos que escapam ao paradigma mental vigente, também ajuda a compreender os riscos do sucesso de outrora para os desejados sucessos vindouros (Martin, 1993; Rego \& Cunha, 2003).

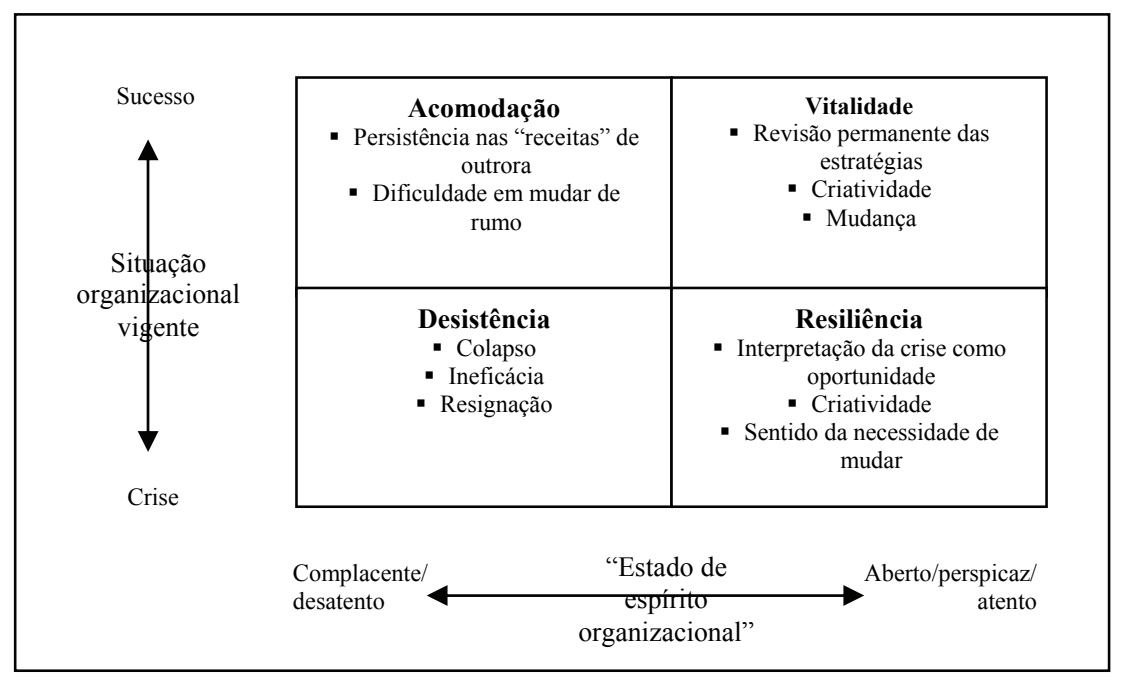

Figura 2: Quatro possíveis “estados de espírito” da organização 
Assim se compreendem algumas razões pelas quais, por vezes, as organizações bem-sucedidas negligenciam os sinais de potenciais ameaças dos concorrentes, seleccionam apenas a informação que corrobora as suas escolhas e negligenciam aquela que as contrariam, permanecem num dado curso de acção, mesmo quando diversos sinais aconselham a mudança de rumo. Em certa medida, também assim se podem compreender as razões pelas quais as organizações sofrem grandes desaires (e.g., desastre do vaivém Challenger) porque insistem num dado curso de acção até agora bem-sucedido - mas ignorando que este sucesso foi obtido em cima de riscos que agora se concretizam. Usando uma analogia: estas organizações actuam como o automobilista insensato que, depois de atravessar ileso inúmeras vezes o semáforo vermelho, se convence de que sempre assim sucederá até ao dia em que é abalroado. É o "sucesso" que o torna cego às possibilidades de catástrofe.

A discussão anterior sugere, pois, várias possibilidades explicativas do movimento de inversão eficácia/ineficácia, podendo aqui salientar-se três:

- Os gestores de organizações eficazes não conseguem, ou não querem, ler os sinais que prenunciam o fracasso. É neste sentido que os gestores de sucesso podem ser considerados a semente do fracasso.

- Os gestores lêem os sinais, mas não são capazes de convencer a organização da necessidade da mudança.

- Os gestores (especialmente os narcisistas) deixam-se "encantar" pelos sucessos passados e desenvolvem uma crença desmedida e irrealista nas suas capacidades, encarando os pequenos desaires que vão surgindo como episódios esporádicos que a realidade acabará por sanar. Enquanto os "buracos" são relativamente pequenos, ocultam-nos ou desenvolvem argumentos que minimizam a sua importância. Mas essa acaba por ser a razão pela qual, a certo momento, o "buraco" começa a ser demasiadamente grande e já não pode ser ocultado. Em certa medida, aqui pode residir uma das explicações para o desmoronamento de colossos como a WorldCom ou a "queda em desgraça" de Mário Conde, no banco Banesto.

Note-se que a primeira destas explicações decorre, em medida considerável, das características cognitivas dos seres humanos, cujas teorias e modelos interpretativos contêm amplas zonas de ignorância e enviesamento voluntário ou involuntário. A ignorância e as explicações simplistas do sucesso facilitam a emergência do fracasso. A análise das envolventes organizacionais é marcada por uma relação dialéctica entre o desconforto gerado pelo novo conhecimento e o conforto decorrente da ignorância (Clegg, 
2006). Esta relação pode ser uma das explicações para a dificuldade de aprendizagem com o fracasso demonstrada na prática empresarial (Baumard $\&$ Starbuck, 2005). No entanto, para evitar crises, a desaprendizagem é necessária (Starbuck, 1996). A eficácia pode, em suma, ser a semente da ineficácia. A organização eficaz pode atingir um tal grau de rigidez na aplicação de "melhores práticas" que as fontes de vantagem se tornam fontes de dêsvantagem (Leonard-Barton, 1992).

\section{Polaridade: ineficácia $\rightarrow$ eficácia}

O movimento contrário ao anterior tem lugar quando a ineficácia é invertida a favor da eficácia. Este é um movimento tanto mais difícil quanto maior a perda de eficácia, pois as crises tendem a suscitar níveis de stress que reduzem os recursos cognitivos da organização. Em todo o caso, as crises de eficácia podem suscitar níveis elevados futuros da mesma. A um nível mais micro, foi isso mesmo que Drucker (1985) referiu quando argumentou que o sucesso inesperado era uma fonte importante de inovação para várias organizações. Em vez de atribuírem as "culpas ao Diabo" ou ao "consumidor irracional", estas empresas procuram descortinar as razões subjacentes ao fracasso - de tal modo que o desaire acaba por surgir como uma boa oportunidade de inovar e obter sucesso.

Para que a inversão seja possível, pode ser necessário defrontar os problemas de forma criativa, eventualmente contra-intuitiva (numa lógica similar à contemplada no adágio "a necessidade aguça o engenho"). Por exemplo, quando uma organização enfrenta uma crise gerada por uma situação de ineficácia, uma das medidas mais prováveis para debelar tal crise consiste em reduzir custos, eventualmente despedindo pessoas e pressionando no sentido da melhoria do desempenho. Todavia, estas medidas podem agravar a crise, já que induzem níveis ainda mais elevados de stress. $O$ foco na acção pode limitar a identificação de soluções criativas justamente quando elas são mais necessárias (Ofori-Dankwa \& Julian, 2004). De modo distinto, o investimento em medidas suscitadoras da criatividade pode, mesmo que aparentemente de forma contra-intuitiva, estimular a identificação de formas inovadoras de abordagem do mercado e, por conseguinte, de novas possibilidades estratégicas (Porter, 1996).

A compreensão do movimento de inversão no sentido ineficácia $\rightarrow$ eficácia é melhor compreendido recordando que o termo "crise" remete, etimologicamente, para a ideia de oportunidade. Hurst (1995) analisou a relação entre crise e renovação, explicitando a necessidade de as organizações se libertarem das amarras do sucesso. O movimento de destruição criativa e deliberada do sistema representa, desta forma, a introdução de uma 
crise, tida como condição necessária para a renovação e a revitalização dos sistemas organizacionais.

A organização ineficaz pode aproveitar a crise (real ou potencial) para despoletar a renovação. As crises reais tendem a gerar níveis elevados de energia psicológica negativa, decorrentes da existência de um alvo claro da agressividade organizacional. A crise pode despertar uma organização até aí resignada e originar um processo de recuperação (Bruch \& Ghoshal, 2003). Não é a crise propriamente dita que gera a oportunidade, mas a percepção da oportunidade de mudança trazida pela crise. As crises também ajudam a credibilizar a apresentação da mudança como urgente e crucial, e facilitam a mobilização colectiva (Kotter, 1996). Pelo contrário, as crises que não são vistas como oportunidades podem gerar desânimo, perda de energia psicológica, sentimentos de resignação e desamparo aprendido. Quando esta sintomatologia se encontra largamente dispersa pela organização, há o risco de esta caminhar passivamente para a sua própria "morte" (Cunha \& Cunha, 2004).

Uma vantagem da crise potencial reside no facto de a mudança poder ser introduzida sem níveis de stress paralisantes. A disrupção introduzida com deliberação pode suscitar mudanças organizacionais facilitadas pela estimulação de energia psicológica positiva - caso a organização seja capaz de conquistar o empenhamento dos membros da organização numa visão partilhada e desejada (Bruch \& Ghoshal, 2003).

A razão pela qual as mudanças ocorrem, por vezes, a destempo, pode ser explicada pelo curso do Tao: apenas quando o extremo da ineficácia é atingido, fica claro para os actores organizacionais que é necessário alterar o rumo dos acontecimentos. Antes disso, embora a possibilidade de sucesso já existisse, o processo poderia ser mais traumático - facto que torna porventura mais tentador aguardar pela oportunidade (o que pode ser problemático se o declínio se tornar irreversível) ou, então, introduzir a disrupção "artificial" que induza os actores a darem as boas vindas à mudança.

As crises organizacionais enfrentadas de forma criativa podem, portanto, originar um "estado de espírito organizacional" vigoroso e resiliente (veja Figura 2) e gerar oportunidades de renovação e de melhoria da organização. E neste sentido que o termo "crise" se aproxima da sua raiz etimológica - o que traduz a possibilidade de, paradoxalmente, a ineficácia de uma estratégia representar a semente da mudança estratégica e, eventualmente, da eficácia.

\section{Conclusões}

Em 1968, W. Ross Ashby escreveu que "[n]um sentido absoluto, não existe aquilo a que se possa chamar a 'boa organização'. Trata-se de uma 
noção sempre relativa; uma organização que é boa num contexto ou de acordo com um critério, pode ser má de acordo com outro" (Scott, 1992, p. 342). A implicação é clara: nenhum critério serve como único ou derradeiro para a avaliação da eficácia de uma organização. A "boa organização" é um estado inalcançável.

A razão para esta "desconfiança" essencial antes aludida passa pelo reconhecimento de que o bom está na origem do mau - e vice-versa. A rejeição do dualismo eficácia $v s$. ineficácia representa uma forma de ultrapassar a simplificação dualista que encara a eficácia como prevalecente sobre a ineficácia. Embora sendo óbvio que a eficácia é o estado desejável, a abordagem dialéctica revela as subtilezas do processo, designadamente:

- A eficácia é um estado potencialmente transitório e não uma condição ou um estatuto organizacional.

- O "curso da natureza" transformará eficácia em ineficácia. E, se houver sagacidade e sabedoria dos actores (ou, usando linguagem taoísta, se houver $T e$ ), poderá transformar a ineficácia e o desaire na eficácia e no sucesso.

- Os líderes eficazes são aqueles que criam sínteses a partir de tensões paradoxais. Que agregam criativamente eficácia e ineficácia - a exploração das aprendizagens anteriores (exploitation) e a aprendizagem por exploração de novos domínios (exploration), experimentos e rotinizações, falhas e sucessos.

- Para compreender as raízes da eficácia é necessário ter consciência das condições da ineficácia - e vice-versa.

- O excesso de uma coisa boa pode ser mau. Enunciando de modo distinto: o excesso de eficácia pode ser prejudicial.

Neste texto, abordámos as questões da eficácia e das "boas organizações", a partir de uma perspectiva paradoxal e dialéctica, ancorada em alguns elementos do sistema de pensamento taoista. Deste modo, procurámos contribuir para a exploração do paradoxo e do pluralismo de perspectivas como elementos centrais da linguagem organizacional contemporânea (Eisenhardt, 2000). Na perspectiva dialéctica aportada pelo taoísmo, o excesso, quer de Yin, quer de Yang, é nocivo. Transportando este princípio para o domínio da eficácia, pode afirmar-se que tanto o excesso de eficácia como o de ineficácia podem ser prejudiciais ao desenvolvimento e à sobrevivência da organização.

Do que fica dito, pode concluir-se que o trabalho da gestão consiste em integrar e compreender tensões e paradoxos, mais do que em simplificar realidades complexas. Ideias como as de "conflito construtivo" (abundantemente dispersas na literatura), "só os paranóicos sobrevivem" (Andrew 
Grove, da Intel), "a ambivalência é a atitude de sabedoria" (Weick, 2001), "erros como oportunidades de aprendizagem" (um dos princípios da 3M) e outras semelhantes revelam a importância de uma abordagem da realidade capaz de reconhecer os estados contraditórios e paradoxais que a caracterizam. Se se aceitar que a ambivalência é a atitude sabedora, ficará claro que: (1) talvez a eficácia nem sempre seja tão positiva como tendemos a considerá-la; (2) talvez a ineficácia não tenha de ser tão negativa quanto tendemos a supor.

\section{Referências}

Banner, D. K. \& Gagné, T. E. (1995). Designing effective organizations: traditional and transformational views. Thousand Oaks: Sage.

Baumard, P. \& Starbuck, W. H. (2005). Learning from failures: why it may not happen. Long Range Planning, 38, 281-298.

Bruch, H. \& Ghoshal, S. (2003). Unleashing organizational energy. MIT Sloan Management Review, Fall, 45-51.

Cameron, K. S. (1986). Effectiveness as paradox: consensus and conflict in conceptions of organizational effectiveness. Management Science, 32, 539-553.

Cameron, K. S. (1984). The effectiveness of ineffectiveness. Research in Organizational Behavior, 6, 235-285.

Capra, F. (1975). The Tao of physics. New York: Wildwood Press.

Chia, R. (2005). Peripheral vision and the entrepreneurial imagination. Trabalho apresentado na SMU EDGE conference, Singapore Management University, Singapura, Julho.

Clegg, S. R. (no prelo). Why is organization theory so ignorant? Journal of Management Inquiry.

Collins, J. C. \& Porras, J. I. (1994). Built to last: successful habits of visionary companies. New York: Harper Business.

Connolly, T., Colon, E. M. \& Deutch, S. J. (1980). Organizational effectiveness: a multiple constituency approach. Academy of Management Review, 5, 211-218.

Cunha, M. P. (2005a). Serendipity: why some organizations are luckier than others. Working paper, Faculdade de Economia, Universidade Nova de Lisboa.

Cunha, M. P. (2005b). Bricolage in organizations. Working paper, Faculdade de Economia, Universidade Nova de Lisboa.

Cunha, M. P. (2006). Paradox. In S. R. Clegg \& J. Bailey (Eds.), International encyclopaedia of organization studies. Thousand Oaks, CA: Sage.

Cunha, M. P., Clegg, S. R. \& Kamoche, K. (no prelo). Surprises in management and organization. British Journal of Management.

Cunha, M. P., Cunha, J. V. \& Kamoche, K. (1999). Organizational improvisation: what, when, how and why. International Journal of Management Reviews, 1, 299-341. 
Cunha, M. P. \& Rego, A. (2004). Estruturas mínimas e mudança organizacional. Tékhne, 1, 9-26.

Cunha, R. C. \& Cunha, M. P. (2004). A bias for inaction: the impact of strategic procrastination on employees and organizational survival. CIMOC Inagural Symposium. City University of Hong Kong, June 2-4.

De Geus, A. (1997). The living company. London: Nicholas Brealey.

Drucker, P. (1985). Innovation and entrepreneurship: practice and principles. Harper \& Row.

Eisenhardt, K. M. (2000). Paradox, spirals, ambivalence: the new language of change and pluralism. Academy of Management Review, 25, 703-705.

Eliot, T. S. (1983). Quatro quartetos. Lisboa: Ática.

Etzioni, A. (1964). Modern organizations. Englewood Cliffs, NJ: Prentice-Hall.

Goodman, P. S., Pennings, J. M. \& Associates (1977). New perspectives on organizational effectiveness. San Francisco: Jossey-Bass.

Greiner, L. E. (1972). Evolution and revolution as organizations grow. Harvard Business Review, 50, 83-92.

Guillén, M. F. (1994). Models of management. Work, authority and organization in comparative perspective. Chicago: University of Chicago Press.

Hannan, M. T. \& Freeman, J. (1977). The population ecology of organizations. American Journal of Sociology, 82, 924-964.

Henri, J. (2004). Performance measurement and organizational effectiveness: bridging the gap. Managerial Finance, 30, 93-123.

Herman, R. D. \& Renz, D. O. (1998). Nonprofit organizational effectiveness: contrasts between especially effective and less effective organizations. Nonprofit Management \& Leadership, 9, 23-38.

Herman, R. D. \& Renz, D. O. (1999). Theses on nonprofit organizational effectiveness. Nonprofit and Voluntary Sector Quarterly, 28, 107-126.

Hurst, D. K. (1995). Crisis and renewal. Meeting the challenge of organizational change. Boston, MA: Harvard Business School Press.

Kaplan, R. E. \& Kaiser, R. B. (2003). Developing versatile leadership. MIT Sloan Management Review, Summer, 19-26.

Kets de Vries, M. F. R. (2005). Leadership: the bright and the dark side of responsibility. EFMD Forum, Summer, 23-26.

Kirby, J. (2005). Toward a theory of high performance. Harvard Business Review, July-August, 30-39.

Kotter, J. P. (1996). Leading change. Boston, MA: Harvard Business School Press.

Langer, E. (1989). Mindfulness. Cambridge, MA: Da Capo.

Lao-Tse (2000). Tao Te King. Lisboa: Estampa.

Lawrence, P. R. \& Lorsch, J. (1967). Organization and environment. Cambridge, MA: Harvard University Press.

Leonard-Barton, D. (1992). Core capabilities and core rigidities: a paradox in managing new product development. Strategic Management Journal, 13, 111-125 . 
March, J. G. (1991). Exploration and exploitation in organizational life. Organization Science, 2, 71-87.

Martin, R. (1993). Changing the mind of corporation. Harvard Business Review, November-December, 81-94.

Meyer, J. W. \& Rowan, B. (1977). Institutionalized organizations: formal structure as myth and ceremony. American Journal of Sociology, 83, 340-363.

Meyer, M. W. \& Gupta, V. (1994). The performance paradox. In B. M. Staw \& L. L. Cummings (Eds.), Research in organizational behavior (vol. 16, pp. 309-369). Greenwich, CT: JAI Press.

Miles, R. H. (1980). Macro organizational behavior. Glenview, IL: Scott, Foresman.

Miller, D. (1990). The icarus paradox: how exceptional companies bring about their own fall. New York: Harper Collins.

Morgan, G. (1986). Images of organization. Thousand Oaks: Sage.

Ofori-Dankwa, J. \& Julian, S. D. (2004). Conceptualizing social science paradoxes using the diversity and similarity curves model: illustrations from the work/play and theory novelty/continuity paradoxes. Human Relations, 57, 1449-1477.

Oldstone-Moore, J. (2005). Taoism. In M. D. Coogan (Ed.), Eastern religions: hinduism, buddhism, taoism, confucianism, shinto (pp. 212-313). New York: Oxford University Press.

Parhizgari, A. M. \& Gilbert, G. R. (2004). Measures of organizational effectiveness: private and public sector performance. Omega: The International Journal of Management Science, 32, 221-229.

Peters, T. \& Waterman, R. (1982). In search of excellence: lessons from America's best-run corporations. New York: Harper \& Row [edição portuguesa: $\mathrm{Na}$ senda da excelência, Lisboa: Dom Quixote, 1987].

Porter, M. E. (1996). What is strategy? Harvard Business Review, 74, 61-78.

Prahalad, C. K. (2004). The blinders of dominant logic. Long Range Planning, 37, 171-179.

Quinn, R. E. \& Rohrbaugh, J. (1983). A spatial model of effectiveness criteria: towards a competing values approach to organizational analysis. Management Science, 29, 363-377.

Rego, A. \& Cunha, M. P. (2003). A essência da liderança. Lisboa: RH Editora.

Scott, W. R. (1992). Organizations: rational, natural, and open systems (3rd ed.). Englewood Cliffs, NJ: Prentice-Hall.

Starbuck, W. H. (1996). Unlearning ineffective or obsolete technologies. International Journal of Technology Management, 11, 725-737.

Thompson, J. D. (1967). Organizations in action. New York: McGraw-Hill.

Tsoukas, H. \& Chia, R. (2002). On organizational becoming: rethinking organizational change. Organization Science, 13, 567-582.

Van de Ven, A. H. \& Poole, M. S. (1995). Explaining development and change in organizations. Academy of Management Review, 20, 510-540. 
Venkatraman, N. \& Ramanujam, V. (1986). Measuring of business performance in strategy research: a comparison approaches. Academy of Management Review, $11,801-814$.

Walton, E. J. \& Dawson, S. (2001). Managers' perceptions of criteria of organizational effectiveness. Journal of Management Studies, 38, 173-199.

Weick, K. E. (1979). The social psychology of organizing (2nd ed.). New York: McGraw-Hill.

Weick, K. E. (2001). Making sense of the organization. London: Blackwell.

Wing, R. L. (1986). O tao do poder. Mem Martins: Lyon Edições.

Yuchtman, E. \& Seashore, S. E. (1967). A system resource approach to organizational effectiveness. American Sociological Review, 32, 891-903. 